\title{
Courting the Future: Cancer and Genetics in Cuba
}

Describing this double issue of MEDICC Review could be an exercise for a first-year philosophy course in logic. It's not about "cancer and genetics" in Cuba. It's about cancer in Cuba and about genetics in Cuba, not about exploring relationships between them.

Nevertheless, while the marriage of the two themes was fortuitous, in that the two had long been scheduled for the journal in 2014 , there is a certain felicity to their sharing an issue. To date, the outstanding accomplishments of genetics have been most helpful for conditions occurring at the beginning of life and cancer is largely (though not exclusively) a disease related to aging. But the two are intrinsically connected: Although only a few of the more than 100 different diseases grouped under the term cancer are known to be hereditary, every cancer begins with a mutation in one or more genes, whether the mutation is inherited, due to an exposure, or is simply a random error in the millions of cell divisions that are part and parcel of cellular reproduction. Our cover image, a stained-glass window by Cuban artist Rosa María de la Terga at Cuba's National Medical Genetics Center, illustrates the elegance of the DNA molecule, the intricate key to life.

The cancer-related articles herein contain material pertinent to the full spectrum of cancer control, from primary prevention to treatment and rehabilitation. Two research articles provide evidence to support decisionmaking at either end of the spectrum (Benet, Smoking Prevalence in Cienfuegos City, Cuba; and Domínguez, Disability-Adjusted Life Years for Breast and Reproductive System Cancers in Cuban Women of Childbearing Age); while González compares Cuban and international policies on cancer screening in Cancer Screening: Global Debates and Cuban Experience, and Lugo reports her work in developing a quality-of-life scale specific to the Cuban context in Development and Evaluation of an Instrument to Measure Health-Related Quality of Life in Cuban Breast Cancer Patients Receiving Radiotherapy.

Lage poses what is effectively a paradigm shift in thinking about cancer: from death sentence to chronic disease (Immunotherapy and Complexity: Overcoming Barriers for Control of Advanced Cancer); and Peña reviews Cuba's progress using its biotechnology capacities for cancer diagnosis and treatment (Immunoscintigraphy and Radioimmunotherapy in Cuba: Experiences with Labeled Monoclonal Antibodies for Cancer Diagnosis and Treatment (1993-2013).

The genetics original research articles cover aspects of antenatal testing in Cuba for various diseases: Collazo, Antenatal Testing for Cystic Fibrosis in Cuba, 1988-2011; Méndez-Rosado, Antenatal Cytogenetic Testing in Havana, Cuba; and Orraca, Neurofibromatosis 1 Prevalence in Children aged 9-11 years, Pinar del Rio Province, Cuba. Rodríguez-Vázquez's Lessons from the Field describes a provincial innovation to improve genetic services (Cuba's Salgen: A Provincial Informatics Network for Genetic Services to Pregnant Women and Newborns). In her Viewpoint, Morales-Peralta argues that, while enormous strides have been made in our ability to test for specific genetic anomalies, there is still no substitute for the physician's clinical judgment (Diagnosis: Genetic Testing Cannot Stand Alone).
This issue's interview with Beatriz Marcheco explores the fascinating genetic mosaic that is today's Cuban population, presenting proof that all Cubans are of mixed ancestry: European-, African- and Native American-origin genes present in each of the island's 11 million inhabitants. Her research traces back generations, to discover the Cuban "Eve" and "Adam." Finally, Marcheco's insights also remind us-as Stephen J. Gould so often and eloquently contended-that all science is rooted in the society, thinking and period in which it is developed. Far from biological determinism, Marcheco posits genetics' potential to offer formidable arguments against racism and its roots.

The panorama is one of optimism, in both cancer and genetics, but many of the technological innovations discussed require investment, and must be backed by robust primary health care systems for detection and triage. For example, one of WHO's criteria for implementing screening programs is that they should be supported by systems that ensure not only diagnosis, but also treatment. This principle could well apply to any testing. A corollary to "first, do no harm" could thus be "do not test, without offering help for what you find."

But how are low-income countries to finance and develop such systems, with so many competing demands on their already tight budgets? Will innovations in disease detection and treatment simply widen existing global health gaps? Public health practitioners have long been aware that population-wide program implementation can exacerbate health inequities if not accompanied by targeted efforts to ensure that they reach beyond already-advantaged groups.

Furthermore, unavailability of medications in the public sector of low-income countries has already been identified as a major contributor to global health inequities, particularly for chronic diseases.[1] And in much of the developing world, universal access to the most basic primary health care services is still more rhetoric than reality. So where do costly new technologies, however effective, fit in with lower-income countries' efforts to meet the health needs of their populations? "Technology triage" to make the most rational use of expensive innovations, coupled with technology transfer among the countries of the Global South-in place in some parts of Latin America and elsewhere, and envisioned by the BRICS agreements-may offer fresh alternatives to address the global health gap.

With this issue of MEDICC Review, we introduce a new online resource for our readers, Facts \& Figures, a compilation of the latest data from Cuba related to the theme of each issue: in this case, one set of statistics on cancer and the other on birth defects. M

\section{The Editors}

1. Cameron A, Roubos I, Ewen M. Mantel-Teeuwisse AK, Leufkens HG, Laing RO. Differences in the availability of medicines for chronic and acute conditions in the public and private sectors of developing countries. Bull World Health Organ. 2011 Jun 1;89(6):412-21. 